\title{
THE IN VITRO EFFECT OF GARDEN THYME (THYMUS VULGARIS L.) EXTRACT ON BRACHYSPIRA HYODYSENTERIAE
}

\author{
JÓZSEF KUTASI ${ }^{1 *}$, LÁSZLÓ JAKAB ${ }^{2}$, VIKTOR JURKOVICH ${ }^{2}$ and PÁL RAFAI ${ }^{2}$ \\ ${ }^{1}$ Dr. Bata Hungarian-Canadian Biotechnological Research-Development Closed Joint \\ Stock Company, Ócsa, Hungary \\ ${ }^{2}$ Department of Animal Hygiene, Faculty of Veterinary Science, Herd-Health and \\ Veterinary Ethology, Szent István University, Budapest, Hungary
}

(Received: 14 November 2015; revised manuscript received: April 25, 2016; accepted: 17 June 2016)

Filtrates of a water extract of commercially available garden thyme (Thymus vulgaris L.) were used for studying its possible bactericidal effect on Brachyspira hyodysenteriae, the causative agent of swine dysentery, by agar-diffusion technique. Five of the six studied Brachyspira strains have proven to be sensitive and one moderately sensitive in the in vitro tests. It was concluded that water extract of garden thyme possesses inhibitory effects against $B$. hyodysenteriae. In vivo experiments are needed to check the validity of this conclusion.

Keywords: garden thyme (Thymus vulgaris L.), Brachyspira hyodysenteriae, bactericidal effect

\section{Introduction}

For decades, increasing interest has been seen for using natural materials, mainly of herb origin, in human and veterinary medicine and in the food, preserving, and cosmetic industries. Numerous reports have been published that describe the composition and effects of these substances [1, 2]. Aromatic herbs and their extracts have been used for ages in traditional systems of medicine [3], and their bactericidal effects have also been known for a long time [4].

Thymus vulgaris L. (garden thyme) is an aromatic perennial herbaceous plant, which belongs to the genus Lamiales and family Lamiaceae. The plant is native to Mediterranean countries, where it blossoms in the period of May-July. In Central European countries, the plant can be cultivated.

\footnotetext{
*Corresponding author; E-mail: biokutasi@gmail.com
} 
The herb contains $1.0 \%-2.5 \%$ volatile oils. The main and most active ingredients of the oil are thymol and its isomer carvacrol, which occur in the oil in a minimum of $40 \%$, with thymol being dominant [5].

Beside volatile oils, thyme also contains several other bioactive substances, such as carotenoids, polyphenols, flavonoids, caffeic and rosmarinic acids, carbohydrates, and triterpenes, which possess free-radical entrapping and anti-oxidative capacity [5-8]. Recently, their anti-inflammatory effect has also been proven $[9,10]$.

The methanolic or aqueous extracts and the essential oil of thyme proved to be antibacterial and antifungal when tested on Gram-positive and Gram-negative bacteria, fungi, and yeasts, e.g., Candida albicans [5]. The effect is seen also when different essential oils were combined [11].

According to our knowledge, no data are available on the effect of thyme against Brachyspira strains. This prompted us to investigate the in vitro effect of the water extract of thyme on the causative agent of swine dysentery (Brachyspira hyodysenteriae).

\section{Materials and Methods}

Water extract

A cold $\left(25^{\circ} \mathrm{C}\right)$ water extract of the herb was produced. Commercially available varieties of $T$. vulgaris $L$. were ground to powder of which $3 \mathrm{~g}$ was added to $100 \mathrm{ml}$ of distilled water then shaken for $1 \mathrm{~h}$ in a bolter. The mixture was ultra sieved through ultra-filter membrane columns (KOCH/Romicon WF2, Hollow Fiber) with a pore size of $500 \mathrm{kDa}$ (filtrate A) and $100 \mathrm{kDa}$ (filtrate B). The filtrates were then used for preparing dilutions up to $1: 20,000$ concentrations.

\section{Microorganism}

The investigation has started with a dose-ranging study involving a strain of B. hyodysenteriae $(\mathrm{B} / 01)$ isolated from a clinically ill fattening pig. Further to this, five other strains originating from the collection of the Department of Microbiology and Infectious Diseases of the Faculty of Veterinary Science, SZIE University have also been included in the investigation.

\section{Isolation and culture media}

All six strains were isolated from pigs that showed clinical signs of swine dysentery in different territorial regions of Hungary. Affected pigs were 
transferred to, then stunned and bled in slaughterhouses. Isolated parts of affected colon sections were transferred to a pathological laboratory. Small amount of colon mucosal scrapes were dispersed over the surface of freshly prepared tryptone-soy culturing media (Sigma-Aldrich, Saint Louis, USA) that contained $10 \%$ defibrinated bovine blood and $400 \mu \mathrm{g} / \mathrm{ml}$ spectinomycin (Sigma-Aldrich, Saint Louis, USA). After inoculation, the plates were incubated for $96 \mathrm{~h}$ at $42{ }^{\circ} \mathrm{C}$ with strict anaerobic conditions. Anaerobic conditions were safeguarded with gasgenerating bags (Oxoid Gas Generating Kit, Anaerobic system BR0038B; Oxoid Ltd., UK) and anaerobic jars (Oxoid Ltd., UK). Determination and identification of the primary and secondary biochemical characteristics of the strains were carried out according to standard methods [12]. The isolated strains were stored deep frozen $\left(-80^{\circ} \mathrm{C}\right)$ in tryptic soy broth that contained $25 \%$ sterile glycerine (Scharlab, S.L., Barcelona, Spain).

Agar-diffusion technique

Blood agar (modified tryptone-soy agar $+10 \%$ defibrinated bovine blood) was used for producing protocultures from thawed mass of bacteria. From each of the protocultures, ten agar cubes of $5 \times 5 \mathrm{~mm}( \pm 5 \%$ deviation) were cut out from the areas showing strong hemolysis. The agar-cube inoculums were spread by sterile glass rod over freshly prepared agar plates of $90 \mathrm{~mm}$ diameter. The plates were closed and dried for $5 \mathrm{~min}$.

According to pre-determined order, a hole of $5 \mathrm{~mm}$ diameter was cut centrally into the inoculated plates. About $100 \mu \mathrm{l}$ of either filtrate of $T$. vulgaris $L$. extract was measured into the holes. The plates were placed into anaerostat (Oxoid Ltd., UK) within 15 min after dripping the known dilution of herb extract into the holes and incubated for $4-5$ days at $37{ }^{\circ} \mathrm{C}$. Inoculations were done in triplicate regarding each dilution per strain.

Sensitivity of Brachyspira strains to the given dilution of the herb extract was estimated on the basis of the average diameters of the growth-inhibition zones that formed around the holes. The inhibition of growth was indicated by the lack of hemolysis, as opposed to a clearance in the blood agar in the areas where growth and hemolysis took place. On this basis, the strains were assorted into three groups as follows:

(1) Sensitive (S): Average diameter of the inhibition ring is $>25 \mathrm{~mm}$, which refers to the in vitro sensitivity of the strain to the given dilution of the herb extract.

(2) Moderately sensitive (MS): Average diameter of the inhibition ring is between 15 and $25 \mathrm{~mm}$, which refers to the questionable effect of the extract at the given solution. 
(3) Resistant (R): Average diameter of the inhibition ring is $<15 \mathrm{~mm}$. This expresses the in vitro inefficiency of the herb solution.

\section{Results}

B. hyodysenteriae is a Gram-negative spirochete, which grows in anaerobic conditions and forms strong beta hemolysis beneath and around the colonies.

Both herb extracts inhibited the growth of B. hyodysenteriae strains proportionally to the dilution rate of the extracts (Table I). As it is seen from Table I, the 1:20,000 dilution of the sample A was found ineffective while the same dilution of the other extract (B) produced MS reaction.

On the basis of this preliminary data, the sample B has proven superior to the other one; therefore, the sensitivity reaction of $B$. hyodysenteriae strains was tested with the 1:5,000 dilution of this sample. Data are disclosed in Table II.

As shown by the data, five of the six B. hyodysenteriae strains $(83.3 \%)$ have proven sensitive and one strain (167/6) gave MS reaction.

\section{Discussion}

Microbicide and fungicide effects of essential oils and different extracts of garden thyme have been studied for a long time. Their efficiency against a large variety of pathogens and food-borne germs has been proven by recent investigations $[11,13,14]$.

Table I. Effect of different dilutions of garden thyme herb extracts on a B. hyodysenteriae strain (B/01) in agar-diffusion tests

\begin{tabular}{lrcc}
\hline $\begin{array}{l}\text { Samples (garden } \\
\text { thyme extracts) }\end{array}$ & Degree of dilution & $\begin{array}{c}\text { Average diameter of the } \\
\text { inhibition ring }(\mathrm{mm})\end{array}$ & Evaluation \\
\hline $\mathrm{A}$ & $500 \times$ & 50 & $\mathrm{~S}$ \\
$1,000 \times$ & 45 & $\mathrm{~S}$ \\
$2,500 \times$ & 36 & $\mathrm{~S}$ \\
$5,000 \times$ & 35 & $\mathrm{~S}$ \\
$10,000 \times$ & 30 & $\mathrm{~S}$ \\
$20,000 \times$ & 15 & $\mathrm{R}$ \\
$500 \times$ & 60 & $\mathrm{~S}$ \\
$1,000 \times$ & 50 & $\mathrm{~S}$ \\
$2,500 \times$ & 47 & $\mathrm{~S}$ \\
$\mathrm{~B}, 000 \times$ & 40 & $\mathrm{~S}$ \\
$10,000 \times$ & 28 & $\mathrm{~S}$ \\
$20,000 \times$ & 25 & $\mathrm{MS}$ \\
\hline
\end{tabular}

Note: $\mathrm{S}=$ sensitive; $\mathrm{MS}=$ moderately sensitive; $\mathrm{R}=$ resistant. 
Table II. Effect of different dilutions of garden thyme herb extracts on different $B$. hyodysenteriae strains in agar-diffusion tests

\begin{tabular}{lccc}
\hline B. hyodysenteriae strains & Sample B and rate of dilution & $\begin{array}{c}\text { Average diameter of the } \\
\text { inhibition ring }(\mathrm{mm})\end{array}$ & Evaluation \\
\hline $167 / 6$ & $5,000 \times$ & 25.0 & $\mathrm{MS}$ \\
$168 / 6$ & $5,000 \times$ & 26.0 & $\mathrm{~S}$ \\
$169 / 6$ & $5,000 \times$ & 31.0 & $\mathrm{~S}$ \\
$170 / 6$ & $5,000 \times$ & 32.0 & $\mathrm{~S}$ \\
$171 / 6$ & $5,000 \times$ & 29.0 & $\mathrm{~S}$ \\
$\mathrm{~B} / 01$ & $5,000 \times$ & 38.0 & $\mathrm{~S}$ \\
Average & & 30.2 & $\mathrm{~S}$ \\
SD \pm & & 4.7 & \\
\hline
\end{tabular}

Note: $\mathrm{S}=$ sensitive; $\mathrm{MS}=$ moderately sensitive; $\mathrm{R}=$ resistant; $\mathrm{SD}=$ standard deviation.

Several of the studies $[1,15,16]$ indicated the sensitivity of Gram-positive bacteria, while others [17-19] have shown expressed sensitivity of Gram-negative bacteria.

In our investigation, a strong dose-dependent effect was observed. This finding is in good agreement with other reports [20-22] involving microbes other than $B$. hyodysenteriae. It is a limitation of our study that the active agents have not been identified and therefore the study is to be viewed as a pilot trial. Antibiotic resistance of the strains was not tested, nevertheless, the results serve as a promising basis for further studies conducted in vivo and on strains with known antibiotic resistance spectrum and known cell count.

Effective substances of garden thyme also affect the antibiotic-resistant microbes [23-26]; in certain cases, they might replace antibiotics [27-29] and might present sound alternative to growth promoters $[4,30]$. These joint effects improve food safety and sustainability of animal agriculture.

\section{Conclusion}

The in vitro investigation reported above seems to support our earlier presumption that water extract of garden thyme possesses antagonistic effects to B. hyodysenteriae. This conclusion, however, should be controlled with further, first of all in vivo experiments in the light that results of the in vitro and in vivo experiments might be different [31].

\section{Conflict of Interest}

The authors declare that they have no conflict of interest. 


\section{References}

1. Kalemba, D., Kunicka, A.: Antibacterial and antifungal properties of essential oils. Curr Med Chem 10, 813-829 (2003).

2. Buchbauer, G., Wallner, I. M.: Essential oils: Properties, composition and health effects. In Caballero, B., Finglas, P. M., Toldrá, F. (eds): Encyclopedia Food Health. Academic Press, Kidlington, UK, 2016, pp. 558-562.

3. Savoia, D.: Plant-derived antimicrobial compounds: Alternatives to antibiotics. Future Microbiol 7, 979-990 (2012).

4. Vondruskova, H., Slamova, R., Trckova, M., Zraly, Z., Pavlik, I.: Alternatives to antibiotic growth promoters in prevention of diarrhoea in weaned piglets: A review. Vet Med 55, 199-224 (2010).

5. European Medicines Agency (EMA): Assessment report on Thymus vulgaris L., vulgaris zygis L., herba. EMA/HMPC/342334/2013 (2013).

6. Braga, P. C., dal Sasso M, Culici, M., Galastri, L., Marceca, M. T., Guffanti, E. E.: Antioxidant potential of thymol determined by chemiluminescence inhibition in human neutrophils and cell-free systems. Pharmacology 76, 61-68 (2006).

7. Proestos, C., Chorianopoulos N., Nychas G. J. E., Komaitis M.: RP-HPLC analysis of the phenolic compounds of plant extracts. Investigation of their antioxidant capacity and antimicrobial activity. J Agric Food Chem 53, 1190-1195 (2005).

8. Martins, N., Barrosa, L., Santos-Buelga, C., Silva, S., Henriques, M., Ferreira, I. C. F. R.: Decoction, infusion and hydroalcoholic extract of cultivated thyme: Antioxidant and antibacterial activities, and phenolic characterisation. Food Chem 167, 131-137 (2015).

9. Braga, P. C., dal Sasso, M., Culici, M., Bianchi, T., Bordoni, L., Marabini, L.: Antiinflammatory activity of thymol: Inhibitory effect on the release of human neutrophil elastase. Pharmacology 77, 130-136 (2006).

10. Khouya, T., Ramchoun, M., Hmidani, A., Amrani, S., Harnafi, H., Benlyas, M., Zegzouti, Y. F., Alem, C.: Anti-inflammatory, anticoagulant and antioxidant effects of aqueous extracts from Moroccan thyme varieties. Asian Pac J Trop Biomed 5, 636-644 (2015).

11. Ghabraie, M., Dang Vu, K., Tata, L., Salmieri, S., Lacroix, M.: Antimicrobial effect of essential oils in combinations against five bacteria and their effect on sensorial quality of ground meat. Food Sci Technol 66, 332-339 (2016).

12. Quinn, P. J., Carter, M. E., Markey, B. K., Carter, G. R.: Clinical Veterinary Microbiology. Wolfe Publishing, London, 1994, pp. 1-648.

13. Angelini, P., Pagiotti, R., Menghini, A., Vianello, B.: Antimicrobial activities of various essential oils against food borne pathogenic or spoilage moulds. Annals Microbiol 56, 65-69 (2006).

14. Arnal-Schnebelen, B., Hadji-Minaglou, F., Peroteau, J. F., Ribeyre, F., Billerbeck, V. G.: Essential oils in infectious gynaecological disease: A statistical study of 658 cases. Int $\mathrm{J}$ Aromatherapy 14, 192-197 (2004).

15. Marino, M., Bersani, C., Comi, G.: Antimicrobial activity of the essential oils of Thymus vulgaris L. measured using a bioimpedometric method. J Food Protect 62, 1017-1023 (1999).

16. Smith-Palmer, A., Stewart, J., Fyfe, L.: Antimicrobial properties of plant essential oils and essences against five important food-borne pathogens. Lett Appl Microbiol 26, 118-122 (1998). 
17. Ashour, A. E. A., El-Astal, Z. Y.: Antimicrobial activity of some Palestinian medical plant extracts: Effect of crude extracts and some of their subfractions. Pak J Biol Sci 8, 1592-1598 (2005).

18. Oussalah, M., Caillet, S., Saucier, L., Lacroix, M.: Antimicrobial effects of selected plant essential oils on the growth of a Pseudomonas putida strain isolated from meat. Meat Sci 73, 236-244 (2006).

19. Penalver, P., Huerta, B., Borge, C., Astorga, R., Romero, R., Perea, A.: Antimicrobial activity of five essential oils against origin strains of the Enterobacteriaceae family. Acta Pathol Microbiol Immunol Scand 113, 1-6 (2005).

20. Czapska, A., Baasinska, B., Szczawinski, J.: Antimicrobial and antioxidant properties of aqueous extracts from selected spice plants. Med Weter 62, 302-305 (2006).

21. El-Astal, Z. Y., Ashour, A. A., Kerrit, A.: Antimicrobial activity of some medicinal plant extracts. West Afr J Pharmacol Drug Res 19, 16-21 (2004).

22. El-Astal, Z. Y., Ashour, A. E. R. A., Kerrit, A. A. M.: Antimicrobial activity of some medicinal plant extracts in Palestine. Pak J Med Sci 21, 187-193 (2005).

23. Friedman, M., Buick, R., Elliott, C. T.: Antibacterial activities of naturally occurring compounds against antibiotic-resistant Bacillus cereus vegetative cells and spores, Escherichia coli, and Staphylococcus aureus. J Food Protect 67, 1774-1778 (2004).

24. Friedman, M., Buick, R., Elliott, C. T.: Antimicrobial activities of plant compounds against antibiotic-resistant Micrococcus luteus. Int J Antimicrob Agents 28, 156-158 (2006).

25. Sienkiewicz, M., Łysakowska, M., Denys, P., Kowalczyk, E.: The antimicrobial activity of thyme essential oil against multidrug resistant clinical bacterial strains. Microb Drug Resist 18, 137-148 (2012).

26. Tohidpour, A., Sattari, M., Omidbaigi, R., Yadegar, A., Nazemi, J.: Antibacterial effect of essential oils from two medicinal plants against Methicillin-resistant Staphylococcus aureus (MRSA). Phytomedicine 17, 142-145 (2010).

27. Urbanczyk, J., Hanczakowska, E., Swiatkiewicz, M.: Herb mixture as an antibiotic substitute in pig feeding. Med Weter 58, 887-889 (2002).

28. Cheng, G., Hao, H., Xie, S., Wang, X., Dai, M., Huang, L., Yuan, Z.: Antibiotic alternatives: The substitution of antibiotics in animal husbandry? Front Microbiol 5, $1-15$ (2014).

29. Kulow, M., Zibaee, F., Allard, M., Döpfer, D.: Short communication: Determination of the ability of Thymox to kill or inhibit various species of microorganisms associated with infectious causes of bovine lameness in vitro. J Dairy Sci 98, 7899-7905 (2015).

30. Khorrami, B., Vakili, A. R., Danesh Mesgaran, M., Klevenhusen, F.: Thyme and cinnamon essential oils: Potential alternatives for monensin as a rumen modifier in beef production systems. Anim Feed Sci Technol 200, 8-16 (2015).

31. Jugl-Chizzola, M., Spergser, J., Schilcher, F., Novak, J., Bucher, A., Gabler, C., Hagmuller, W., Zitterl-Eglseer, K.: Effects of Thymus vulgaris $L$. as feed additive in piglets and against haemolytic E. coli in vitro. Berlin Munchen Tierarzt Wochenschrift 118, 495-501 (2005). 